\title{
Assessment and Comparison of New and Old Carbon Filters for Contaminants Removal: Antwerp Coca Cola plant, Belgium
}

\author{
Zinabu Tebeje Zewdu \\ UNESCO-IHE, P. O. Box 3015, 2601 DA Delft, the Netherlands (Zinabut@yahoo.com)
}

\begin{abstract}
Coca-Cola's water quality criteria for carbonated beverage process water include an absence of chlorine residual and total trihalomethanes (THMs) below the local drinking water standard or, in the absence of a local standard, the WHO standard is used. Presence of chlorine residual in feed water used for production of carbonated beverage process water is of a concern as chlorine free water is needed for production of carbonated beverages. GAC is used in the bottling industry primarily for de-chlorination of municipal chlorinated water and/or process water subjected to inplant chlorination at chlorine doses of several $\mathrm{mg} / \mathrm{L}$. In addition to de-chlorination GAC is also required for the removal of THMs. This study assessed the proportion of chlorine, TOC and THMs' before and after the GAC filters. It also compared the removal efficiency of two weeks and four year GAC filters and finally evaluated the effectiveness of steam regeneration of GAC. Samples were taken from before the treatment plant and influent and effluent of the GAC filters for the analysis of TOC, UV and THMs determination. The result showed that $8.8 \%$ TOC removal in the filters and based on the SUVA value. The low removal of TOC was related to non humic substance, relatively low hydrophobicity, less aromatic and of lower molecular weight of the TOC. Comparison of two week and four years in service old GAC reveals THMs breakthrough of 3.8 and $58 \%$ at the end of one steam regeneration cycle for EBCT of 2.41. This suggests that steam regeneration is only partially recovering THMs adsorption capacity.
\end{abstract}

Key words: Granular activated carbon (GAC), Multi-component Adsorption, Treatment Plant, Bromoform, De-chlorination and Trihalomethanes (THMs).

\section{INTRODUCTION}

In many developing and developed countries drinking water quality is an issue to safeguard human health. Water contains different contaminants that can be harmful to human health. One of the contaminants of concern is microbiological quality which is controlled by disinfection process (Tebeje, 2010). A disinfectant chemical like chlorine is chosen since it is cheap and strong disinfectant(Roy, 1995, Tebeje, 2011). According to WHO, an estimated 1.7 million deaths a year are attributed to unsafe water supplies due to waterborne diseases and pathogenicorganisms. In the late 1800s and early 1900s chlorination and filtration were introduced and developed due to the occurrence of water born diseases like cholera and typhoid. Disinfection and filtration were enhanced by more elaborated pretreatment due to identification of Legionella, cryptosporidium, and giardia. More specialized processes like Granular activated carbon (GAC) 
were occasionally applied to water treatment to control taste and odor causing compounds and to remove contaminants (Kim and Kang, 2008; Letterman, 1999; Liet al., 1997).

In 1974, researchers in the Netherlands and the United States (USEPA, 1999) demonstrated that trihalomethanes (THMs) were being formed from the interaction of chlorine/ bromide with various organic substances in the water. THMs cause cancer, miscarriages and they are mutagenic. Studies also linked THMs to heart, lung, kidney, liver and central nervous system damage. Despite the health risk of THMs, it is a serious issue when the large population being exposed is considered ( Edward, 2005; Metcalf and Eddy, 2006; Qasimet al., 2004).

\subsection{Water treatment on beverage process water}

Beverage water treatments include different treatment steps for the production of best quality processing water. Among the common treatment steps applied in beverage industries are coagulation, flocculation, ion exchange, disinfection, and filtration. Coca-Cole Company applies disinfection system to control microorganisms and carbon purification for reduction/ removal of taste, odor, organics and chlorine. After GAC filter the treatment plant apply polishing filtration to control appearance.

\subsection{Antwerp Treatment Plant, Belgium}

Antwerp treatment plant has a capacity of $120 \mathrm{~m}^{3} /$ hour and the treatment scheme incorporates flocculation, hydroantracite filter, ion exchange, chlorination, buffer tanks, activated carbon, polishing filtration and deareation units (Fig. 1).

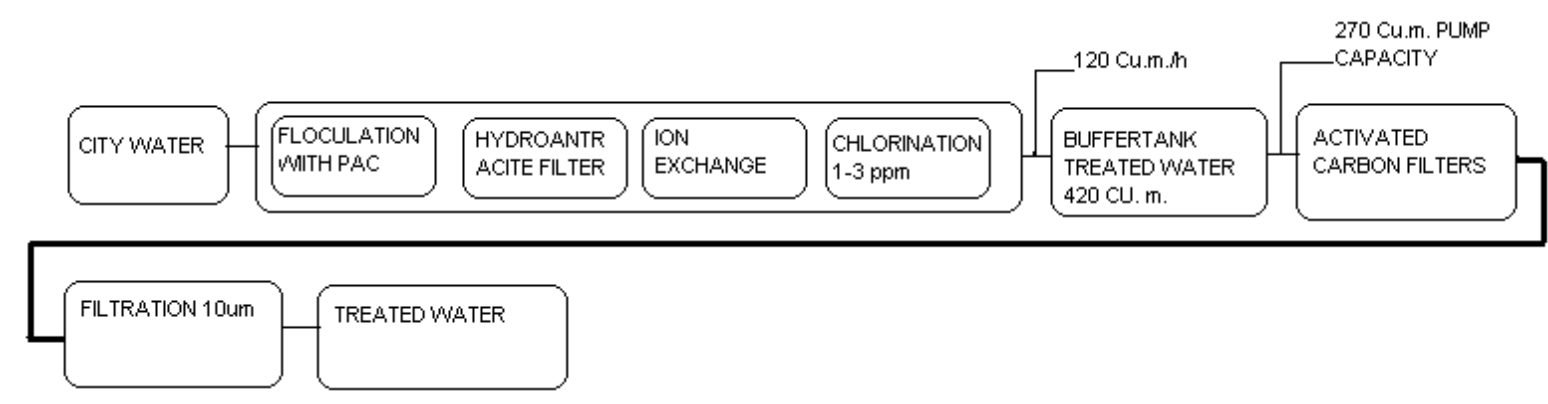

Figure 1. Process flow of treated water, actual situation of Coca-Cola Treatment plant in Antwerp.

Coca-Cola Company of Antwerp receives chlorinated $\left(0.02 \mathrm{mg} / \mathrm{l}\right.$, total chlorine as $\left.\mathrm{Cl}_{2}\right)$ city water of Antwerp with THMs concentration reaching up to a level of $73 \mu \mathrm{g} / \mathrm{l}$. On top of the chlorine residual in the Antwerp municipal city water, Coca-Cola Company treatment plant also applies additional chlorination (1-3 mg/l) as a safety measure. The chlorine residual cause a negative 
impact on the processing water and has a risk of THMs formation. To address this, the treatment plant has three granular activated carbon (GAC) filters operated in parallel figure 2 with different age of filter media (new to four years old). The GAC is replaced typically once in four years.

Coca-Cola has a guideline for THMs of $100 \mu \mathrm{g} / \mathrm{l}$. GAC filtration used by the Coca-cola water treatment plant differs from the municipal drinking water practice in a number of ways. First, only virgin, not thermally regenerated, GAC is used. Second, steam and/or high-temperature water is used weekly to sterilize the GAC (to inhibit microbial activity) as well as to regenerate THMs adsorption capacity. And last, GAC filters are periodically backwashed based on a regular maintenance schedule.

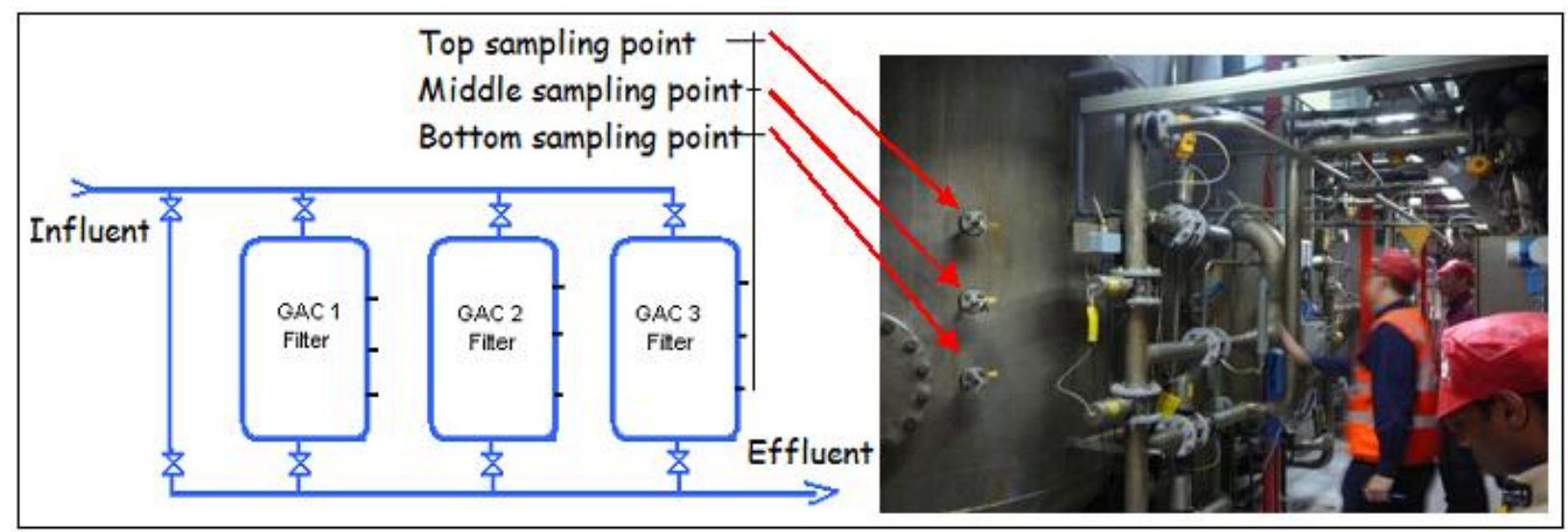

Figure 2. Three parallel GAC filters in the Coca-Cola treatment plant, in Antwerp; Filtrasorb 200 GAC, 1.18m media depth, 7.12 min EBCT.

GAC filters need to be backwashed to remove particulate debris that accumulates on the surface of the GAC and to prevent channeling and short circuiting of water via filter bed (Liu and Han, 2007; Macquarrie and Wilton, 2002). One factor that introduces the need for GAC backwashing is formation of calcium carbonate in the bed. Calcium in the form of $\mathrm{CaO}$ exists in all activated (or reactivated) carbon types which are available in the market which causes deposition of calcium carbonate in the bed of GAC (Orlandini, 1999). In the past the backwashing of GAC filter was done once in two weeks. However, better removal of microbes was obtained when frequency of the backwash was recently increased to once per week. The regeneration of GAC media in the Antwerp treatment plant is based on use of hot water at a temperature of $85-95^{\circ} \mathrm{C}$ for $6 \mathrm{hrs}$ at a pressure of 4 bars. Backwashing of filter media is applied before and after regeneration, where the second backwash serves for cooling of the media. The company has a plan to lower the life time of filters from four years to three years and to change one filter media 
per yearto keep optimum removal efficiency. The treatment plant has a plan to install UV disinfection and polishing membrane filtration of $10 \mu \mathrm{m}$ after GAC filter, which will help in the removal of micro organisms possibly present in the treated water after GAC filters. Dechlorination by GAC makes the GAC more brittle because it destroys some of the GAC by chemical reduction. Brittle carbon is then sensitive to increased breakup during backwashing leading to operational problem due to high head loss development. To avoid frequent backwash due to head loss development, GAC of $12 \times 40$ US Standard mesh $(1.68 \times 0.42 \mathrm{~mm})$ or similar activated carbon is used (Edward, 2005; Letterman, 1999).

Presence of chlorine residual in feed water used for production of carbonated beverage process water is of a concern as chlorine free water is needed for production of carbonated beverages.GAC is used in the bottling industry primarily for de-chlorination of municipal chlorinated water and/or process water subjected to in-plant chlorination at chlorine doses of several $\mathrm{mg} / \mathrm{L}$.In addition to de-chlorination GAC is also required for the removal of THMs. Coca-Cola's water quality criteria for carbonated beverage process water stipulates chlorine residual of $0 \mathrm{mg} / \mathrm{l}$ and THMs below $100 \mu \mathrm{g} / \mathrm{l}$. This study assessed first the proportion of chlorine, TOC and THM's before and after the GAC filters. Second, it compared the removal efficiency of GAC filters and removal efficiency of new and old GAC filters. And finally, it assessed the effectiveness of steam regeneration of GAC as applied in full scale Coca-Cola water treatment plant, in Antwerp.

\section{ANALYTICAL INSTRUMENTS AND ANALYSIS}

In the Antwerp Coca-Cola treatment plant three GAC filters of $2.2 \mathrm{~m}$ diameter and media depth of $1.18 \mathrm{~m}$ are operational. Each filter is filled with $4.5 \mathrm{~m}^{3}$ of Calgon F200 GAC (the physical properties are listed in Table 1). The full scale GAC filters have three sampling points at about 40 $\mathrm{cm}$ intervals: top; middle and bottom along the depth as shown in figure 3 . For the analysis of THMs samples were taken from old (four year service) and new filter media (two weeks service) at five different sampling points; three points along the filter depth, and one before and one after the GAC filters. 


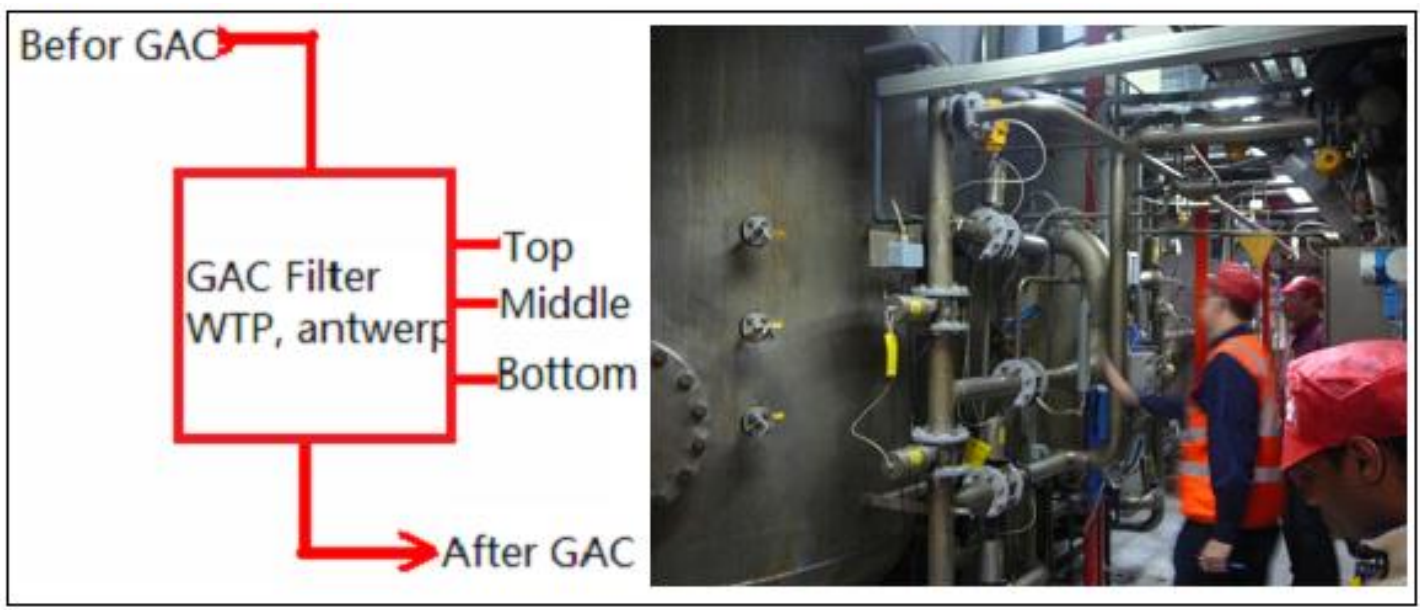

Figure 3. Schematic (left) and a photo of sampling points on the GAC filters of full-scale, in Coca-Cola treatment plant, Antwerp.

Table 1. Characteristics of activated carbon utilized in Antwerp Coca Cola Company.

\begin{tabular}{|lll|}
\hline GAC name & & Calgon F200 \\
\hline Particle size > 12 mesh $(1.70 \mathrm{~mm})$ & mass-\% & 5 \\
\hline Particle size < 40 mesh $(0.425 \mathrm{~mm})$ & mass-\% & 4 \\
\hline Moisture (as packed) & mass-\% & 2 \\
\hline Iodine number & - & 850 \\
\hline Total surface area (B.E.T.) & $\mathrm{m} 2 / \mathrm{g}$ & 850 \\
\hline Density backwashed and drained & $\mathrm{kg} / \mathrm{m} 3$ & 500 \\
\hline Ball-pan hardness & - & 95 \\
\hline Effective Size D10 & $\mathrm{Mm}$ & $0.6-0.8$ \\
\hline Uniformity coefficient & - & 1.7 \\
\hline Dechlorination halving value & $\mathrm{Cm}$ & 2 \\
\hline
\end{tabular}

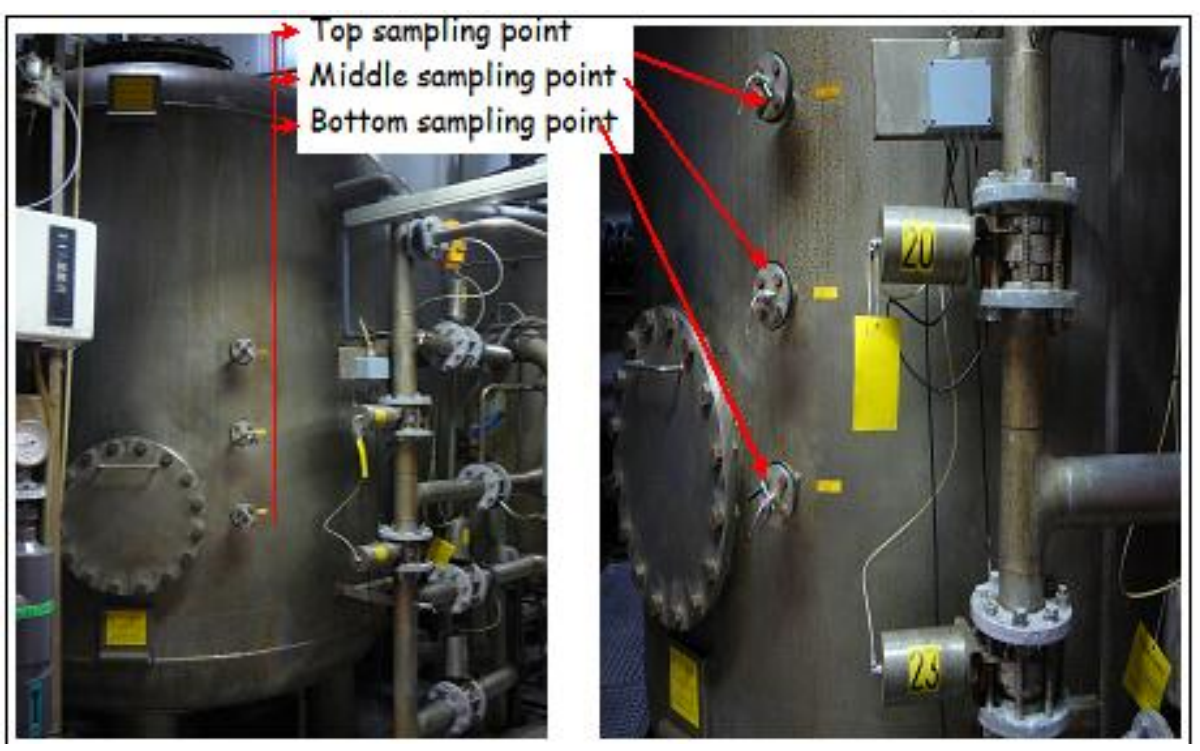

Figure 4. Three sampling points, along depth of GAC filter. 


\subsection{Spectrophotometer and TOC analyzer}

\subsubsection{UV absorbance (UVA515)}

Spectrophotometer was used at a wave length of $515 \mathrm{~nm}$ to calibrate chlorine measuring test kit. De-mineralized sample was used as a blank in $1 \mathrm{~cm}$ of quartz cell and run at the start of the measurement to auto zero the spectrometer. Care has been taken not to have stain on the surface and air bubbles inside of the cell wall, as these affect the measurement. Cuvett was flushed thoroughly with Milli-Q water between samples and was rinsed with each sample before being filled. Finally the absorbance reading was recorded immediately to avoid error due to volatility of chlorine.

\subsubsection{UV absorbance (UVA254)}

UV absorbance measurement at a wavelength of $254 \mathrm{~nm}$ was carried out by Perkin Elmer UV/VIS Spectrophotometer using $1 \mathrm{~cm}$ cell of type QS suitable for wavelength below $300 \mathrm{~nm}$. Care has been taken not to have stain on the surface and air bubbles inside of the cell wall, as these affect the measurement. Cuvett was flushed thoroughly with Milli-Q water between samples and was rinsed with each sample before being filled.

\subsubsection{TOC analyzer}

TOC measurements were conducted to reflect the natural organic matter content of the raw water using Dohrmann DC-180 Total Organic Carbon Analyzer (USA). The TOC determination procedure followed that outlined in Standard Method No. 5310C in (APHA, 1998).

\subsection{Gas Chromatography}

Gas chromatography (GC) method use headspace for the determination of volatile halogenated hydrocarbons in the samples. Chloroform was detected by an electron capture detector (ECD). Identification was based on retention time while quantification is based on the intensity of the ECD signal using a five-point calibration. During sample preparation $5 \mathrm{ml}$ of sample using pipette was added into a $20 \mathrm{~mL}$ headspace vial and the vial was closed with a crimp cap with a silicon septum. The sample was heated in a closed headspace vial in order to obtain equilibrium between the concentration of the volatile halogenated hydrocarbons in the headspace above the sample and the concentration in the sample. By purging the headspace with Helium, the volatile hydrocarbons in the headspace were transferred to the GC where they were separated. The components were detected by an ECD and calibration curve and control standards were observed using software (Turbochrom). Identification was based on retention time (5.26 minutes and 
11.16 minutes for chloroform and bromoform respectively) while quantification was based on the intensity of the ECD-signal using a five-point calibration. These retention times slightly vary due to aging of the column and were corrected. The quantification of the components was done automatically by the software using linear regression of the second order. When the results were below the detection limit it was expressed as less than $0.5 \mu \mathrm{g} / \mathrm{L}$ and $2 \mu \mathrm{g} / \mathrm{L}$ for concentration of Chloroform and THMs respectively. But, when the result of one of the components was more than $50 \mu \mathrm{g} / \mathrm{L}$, the samples were diluted and re-analyzed.

\section{RESULTS AND DISCUSSION}

Results obtained from full scale plant in Antwerp Coca-Cola Company are presented and discussed as follows.

\subsection{Assessment of full scale GAC filters at Coca-Cola Plant in Antwerp}

For removal of chlorine residual and THMs Antwerp treatment plant applies granular activated carbon (GAC) filters. In the treatment plant weekly steam regeneration is applied for microbial sterilization and removal of chlorine and/or THMs. Samples were taken from Antwerp CocaCola plant and onsite measurement of $\mathrm{pH}$ and laboratory measurement of TOC and $\mathrm{UV}_{254}$ were analyzed and tabulated in table 2 . The result showed $31 \%$ TOC removal from the inlet of the municipal drinking water (inlet to treatment plant) up to the inlet of GAC filter. On the other hand only $8.8 \%$ TOC removal was achieved inside the GAC filters.

Table 2. Organics and $\mathrm{pH}$ at Coca-Cola treatment plant in Antwerp.

\begin{tabular}{|l|l|l|l|}
\hline Parameters & City water & GAC feed & GAC effluent \\
\hline $\mathrm{pH}$ & 7.74 & 6.59 & 6.51 \\
\hline $\mathrm{TOC}(\mathrm{mg} / \mathrm{L})$ & 2.64 & 1.82 & 1.66 \\
\hline $\mathrm{UV}_{254}\left(\mathrm{~cm}^{-1}\right)$ & 0.028 & 0.025 & 0.021 \\
\hline SUVA $(\mathrm{L} / \mathrm{m}-\mathrm{mgC})$ & 1.06 & 1.37 & 1.27 \\
\hline
\end{tabular}

The SUVA value was computed by dividing $\mathrm{UV}_{254}\left(\mathrm{~cm}^{-1}\right)$ by $\mathrm{TOC}(\mathrm{mg} / \mathrm{L})$. When the SUVA value is less than $3 \mathrm{~L} / \mathrm{m}-\mathrm{mgC}$, the effect of TOC on the coagulant dosage may be negligible and relatively low removal percentage( 20-50\%) are likely (Kim and Kang, 2008). Hence the result showed that the upstream treatment before GAC filter, removes the TOC efficiently (31\%). On 
the other hand the TOC removal of GAC was not effective due to the non humic nature, relatively low hydrophobicity, less aromatic and of lower molecular weight of the TOC which is indicated by the low SUVA value $(<2 \mathrm{~L} / \mathrm{m}-\mathrm{mgC})$. The other reason for the low removal of TOC by GAC media could be the lower EBCT (Crittenden et al., 1989, Letterman, 1999).

\subsection{Chlorine concentration in the plant}

The Coca-Cola treatment plant receives city water of Antwerp which has been chlorinated for the purpose of disinfection. In the treatment plant also chlorination (1-3ppm) is applied as a safety measure. The free chlorine concentration after GAC filtration is consistently below the detection limit of $0.02 \mathrm{mg} / \mathrm{l}$ which shows effective removal of chlorine by GAC filters.

\subsection{THMs concentration in the plant}

The study focused on the four common types of THMs covered by the regulations; namely chloroform $\left(\mathrm{CHCl}_{3}\right)$, bromodichloromethane (BDCM), dibromochloromethane (DBCM) and bromoformCHBr $\mathrm{CH}_{3}$. The result showed at the Coca-Cola treatment plant in Antwerp all four common THMs species were present. In the upstream of GAC filter with the highest concentration $(18.89 \pm 3.53 \mu \mathrm{g} / \mathrm{L})$ of bromodichloromethane (BDCM) and the lowest concentration of bromoform $(4.00 \pm 0.60 \mu \mathrm{g} / \mathrm{L})$. However, after GAC the concentration of THMs species was found to be in the order: $\mathrm{CHCl}_{3}>\mathrm{CHBrCl}_{2}>\mathrm{CHBr}_{2} \mathrm{Cl}>\mathrm{CHBr}_{3}$.

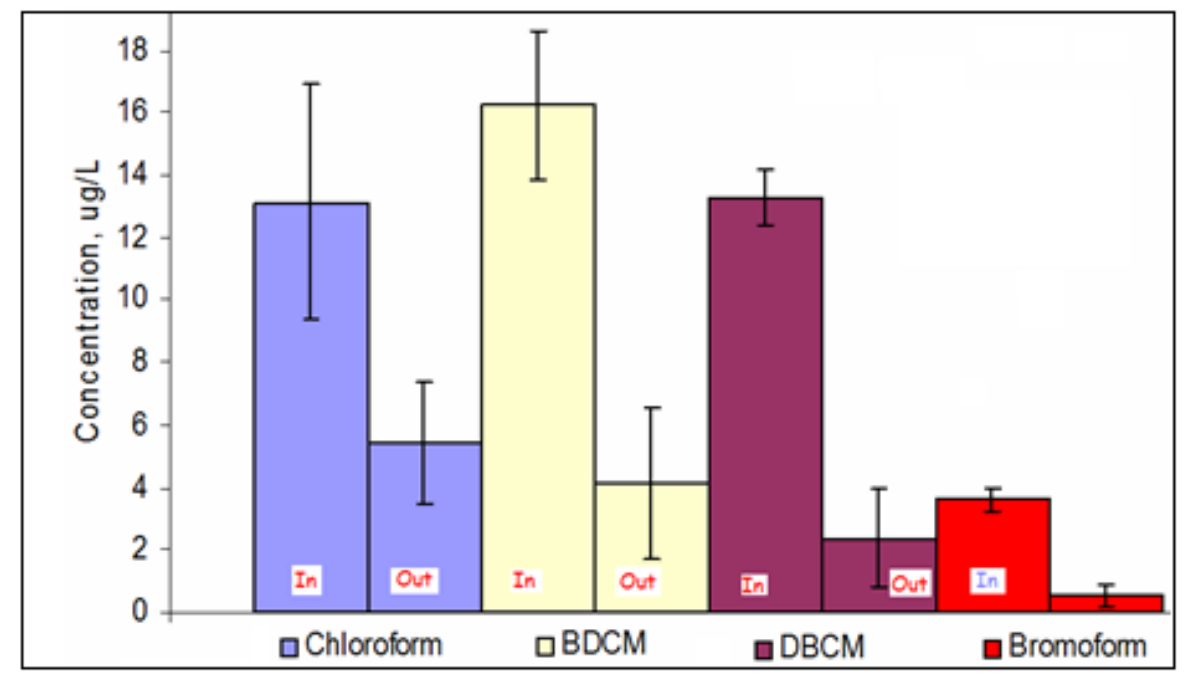

Figure 5. Removal of Different THMs in top $40 \mathrm{~cm}$ of full scale GAC (four years in service) in Coca-Cola Plant, Antwerp.

The more chlorine present in the THMs structure, the more difficult would be its removal with GAC resulting in faster breakthrough as shown in figure 5. Previous results at the plant showed 
also same order of removal of THMs by GAC filter as shown in table 3and also the city water concentration of THMs is not uniform. The reason for this might be the seasonal variation of TOC in the source water. The result is in agreement of previous researches to mention Potwora (2006) also showed the brominated methane's are more strongly adsorbed than chloroform.

Table 3. THMs in feed and treated water of Coca-Cola treatment plant in Antwerp, analysis by Brussels Coca-Cola laboratory.

\begin{tabular}{|llllllll|}
\hline Parameter & Unit & $\mathbf{1 1 / 2 0 0 5}$ & $\mathbf{0 9 / 2 0 0 6}$ & $\mathbf{0 3 / 2 0 0 7}$ \\
\hline & & $\mathrm{A}$ & $\mathrm{B}$ & $\mathrm{A}$ & $\mathrm{B}$ & $\mathrm{A}$ & $\mathrm{B}$ \\
\hline Bromide as $\mathrm{Br}$ & $\mu \mathrm{g} / 1$ & 25 & 26 & 30 & 68 & 54 & 30 \\
\hline Bromoform & $\mu \mathrm{g} / \mathrm{l}$ & 6.3 & 1.6 & 12.7 & 2.2 & 8.8 & 2.2 \\
\hline Dibromochloromethane & $\mu \mathrm{g} / 1$ & 15.6 & 1.5 & 21 & 5.1 & 13 & 8.5 \\
\hline Bromodichloromethane & $\mu \mathrm{g} / 1$ & 15 & 9.1 & 25.8 & 4.6 & 9.8 & 9.7 \\
\hline Chloroform & $\mu \mathrm{g} / 1$ & 8.4 & 6.8 & 13.7 & 1.1 & 6.8 & 7.6 \\
\hline THMs & $\mu \mathrm{g} / 1$ & 45.3 & 23 & 73.2 & 13 & 38.4 & 28 \\
\hline A: City water entrance to the plant & \multicolumn{4}{c}{ B: Treated water after GAC filters } \\
\hline
\end{tabular}

\subsection{THMs removal with fresh GAC filter media}

One GAC filter of two weeks service filled with Calgon F200 media were considered for this study. Samples were taken, from the filter with new GAC media, during two consequent filter run cycles of one week followed by steam regeneration. In addition, one additional sample was taken at the start of the third regeneration cycle. Due to limited number of samples that had been analyzed in the laboratory, effluent samples were taken only for the top sampling point. Top sampling point is chosen to get much pronounced effect of the breakthrough curve. The THMs removal efficiency of new GAC media is reasonably high (about $97 \%$ removal of THMs per one regeneration cycle), but still there were some levels of THMs residuals after the filter is regenerated.

Results shown in figure 6 and figure 7 clearly show that the chloroform appears first in the treated water which indicates that GAC has lower capacity for chloroform. Figure 6 shows THMs breakthrough where as Figure 7 shows breakthrough of each species. Figure 7 shows result also showed 88 and $100 \%$ removal capacity for chloroform and bromoform respectively for the top $40 \mathrm{~cm}$ depth of GAC media. THMs breakthrough reaches only 8 percent $(4.8 \mu \mathrm{g}$ $\mathrm{THMs} / \mathrm{L}$ ) in the TOP $40 \mathrm{~cm}$ of new GAC media after regeneration period. Hence, frequent steam regeneration is not desirable for a primary target of THMs removal. The result shows chloroform 
(less adsorbed) breakthrough 12 percent $(3.4 \mu \mathrm{g} / \mathrm{L})$ in the top $40 \mathrm{~cm}$ before the third regeneration and 5 percent breakthrough $(1.1 \mu \mathrm{g} / \mathrm{L})$ after regeneration, which shows that regeneration could not remove all the THMs but can remove to a desired level.

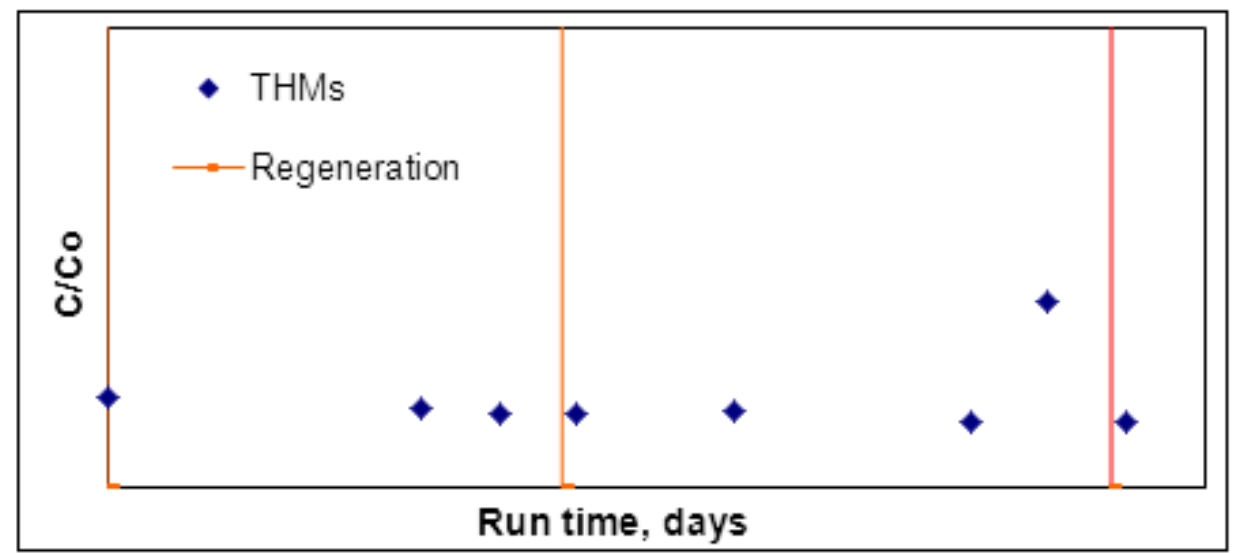

Figure 6. Effect of filter runtime and steam regeneration on THMs concentration at top sampling point ( $40 \mathrm{~cm}$ depth) of full-scale GAC; filter with new media ( one week in service) Coca-Cola Plant, Antwerp; Feed water: deionised water, $\mathrm{Co}=59.75 \pm 8.65 \mu \mathrm{g}$ THMs $/ \mathrm{L}$, $\mathrm{pH}=7.0 \pm 0.2$.

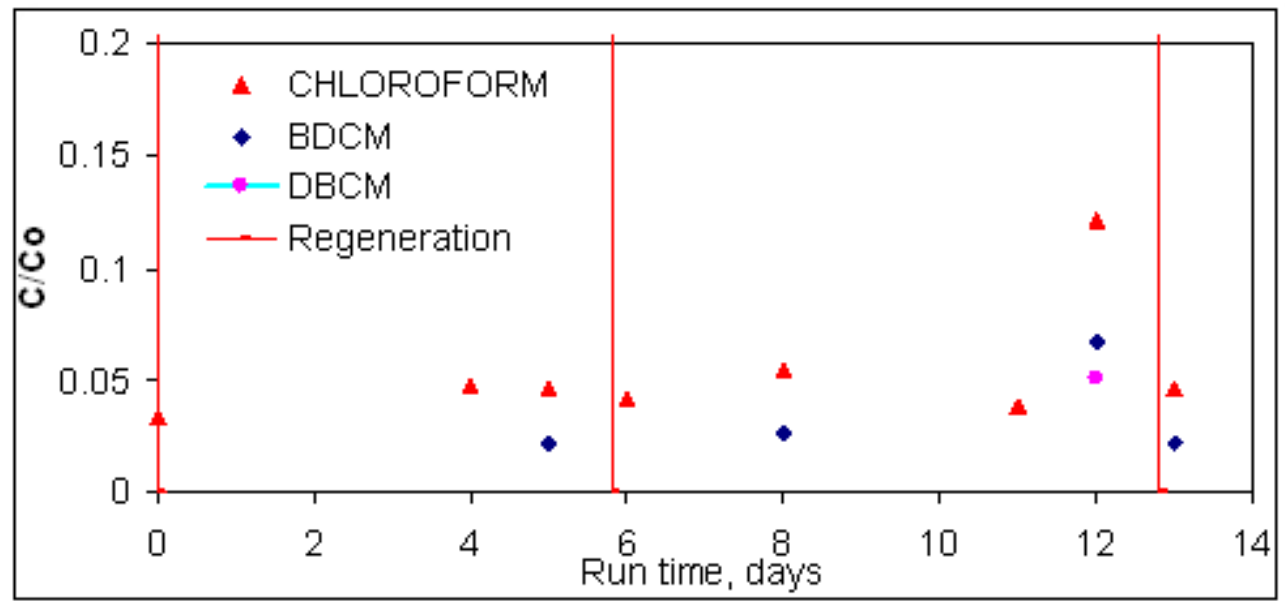

Figure 7. Effect of filter runtime and steam regeneration on concentration of different THMs species at top sampling point (40 cm depth) of full-scale GAC; filter with new media (one week in service) Coca-Cola Plant, Antwerp; Feed water: deionized water, Co, chloroform $=20.80 \pm 3.10 \mu \mathrm{g} / \mathrm{L}, \mathrm{Co}, \mathrm{BDCM}=20.50 \pm 2.50 \mu \mathrm{g} / \mathrm{L}, \mathrm{Co}, \mathrm{DBCM}=14.60 \pm$ $2.10 \mu \mathrm{g} / \mathrm{L}, \mathrm{pH}=7.0 \pm 0.2$

\subsection{THMs' removal with GAC, four year in service}

The Coca-Cola design guidelines recommend life span of GAC filter media of five years. One of the three GAC filters in Antwerp was in operation for four years at the time of sampling 
conducted in this study. Samples taken from the top sampling point $(40 \mathrm{~cm}$ of GAC media corresponding to EBCT of $2.41 \mathrm{~min}$ ) from the filter that has been in service for four years showed up to 58 percent of breakthrough of THMs per one regeneration cycle as shown in figure 8 and figure 9.

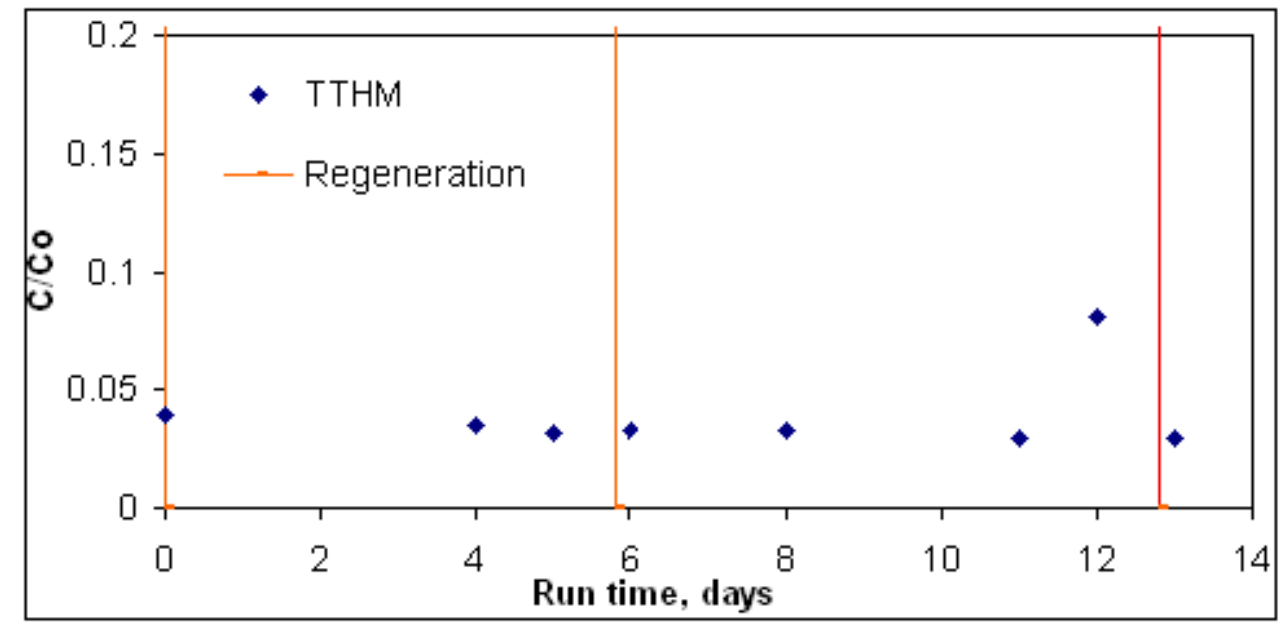

Figure 8. Effect of filter runtime and steam regeneration on THMs concentration at top sampling point (40cm depth) of full-scale GAC filter with old media (four year in service) CocaCola Plant, Antwerp; Feed water: deionised water, $\mathrm{Co}=50.70 \pm 4.80 \mu \mathrm{g}$ THMs $/ \mathrm{L}$.

Analysis of THMs species in filtrate taken at the top sampling point for GAC filters with filter media four year in service showed chloroform and bromoform breakthrough of up to 80 and 40 $\%$ respectively. The result confirmed that the more chlorine attached to a THMs species the less it is adsorbed on GAC.

Chloroform breakthrough was increased from 3 to 20 percent in the top $40 \mathrm{~cm}$ for the two week and four year old filter media respectively. Similarly bromoform was completely absorbed in one week service filter and breakthrough of 40 percent was observed for four year service GAC media at the top $40 \mathrm{~cm}$. This shows that the ineffectiveness of steam regeneration for removal of THMs species.

The removal of THMs with old GAC media along the bed depth is shown in Figure 10. It is observed that 60 percent and 14 percent THMs' breakthrough occurred for EBCT of $2.41 \mathrm{~min}$ (top sampling point) and 7.12 minute (GAC effluent water) respectively showing removal efficiency of 77 percent between top sampling point and effluent water. This is due to ineffective long term steam regeneration and also possibly due to trapped contaminants that blocked the micro-pores. 


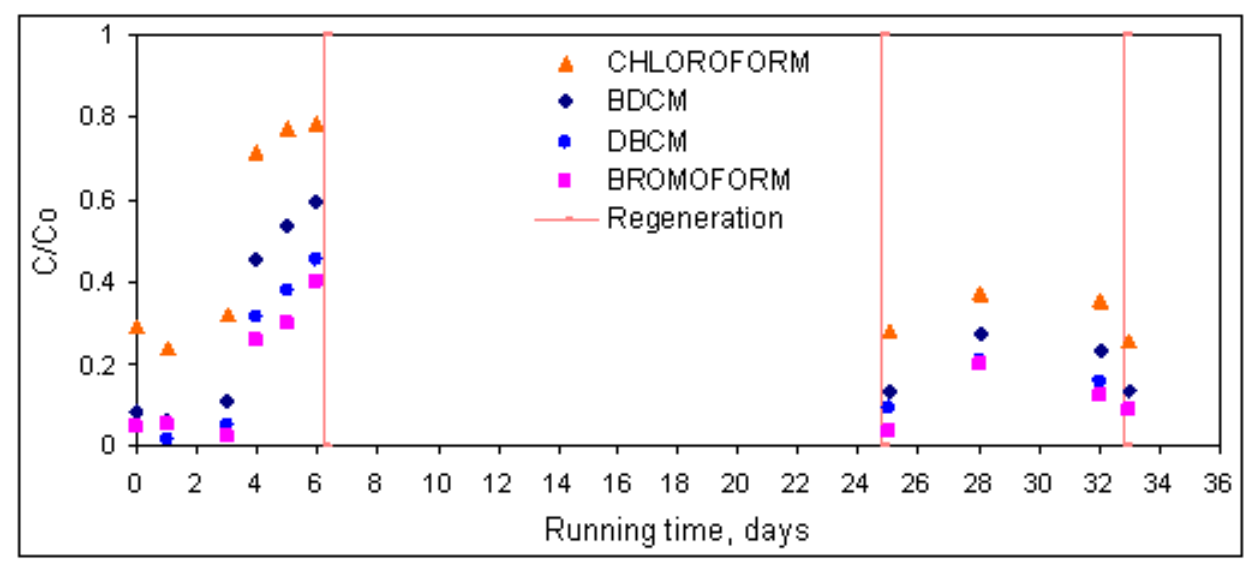

Figure 9. Effect of filter runtime and steam regeneration on concentration of different THMs species at top sampling point (40cm depth) of full-scale GAC; filter with old media (four year in service) Coca-Cola Plant, Coca-Cola Plant, Antwerp, Feed water: Co, Chloroform $=14.95 \pm 5.35 \mu \mathrm{g} / \mathrm{L}, \mathrm{Co}, \mathrm{BDCM}=17.80 \pm 3.50 \mu \mathrm{g} / \mathrm{L}, \mathrm{Co}, \mathrm{DBCM}=14.20 \pm$ $1.10 \mu \mathrm{g} / \mathrm{L}, \mathrm{Co}$, Bromoform $=3.80 \pm 0.30 \mu \mathrm{g} / \mathrm{L}, \mathrm{pH}=7.0 \pm 0.2$.

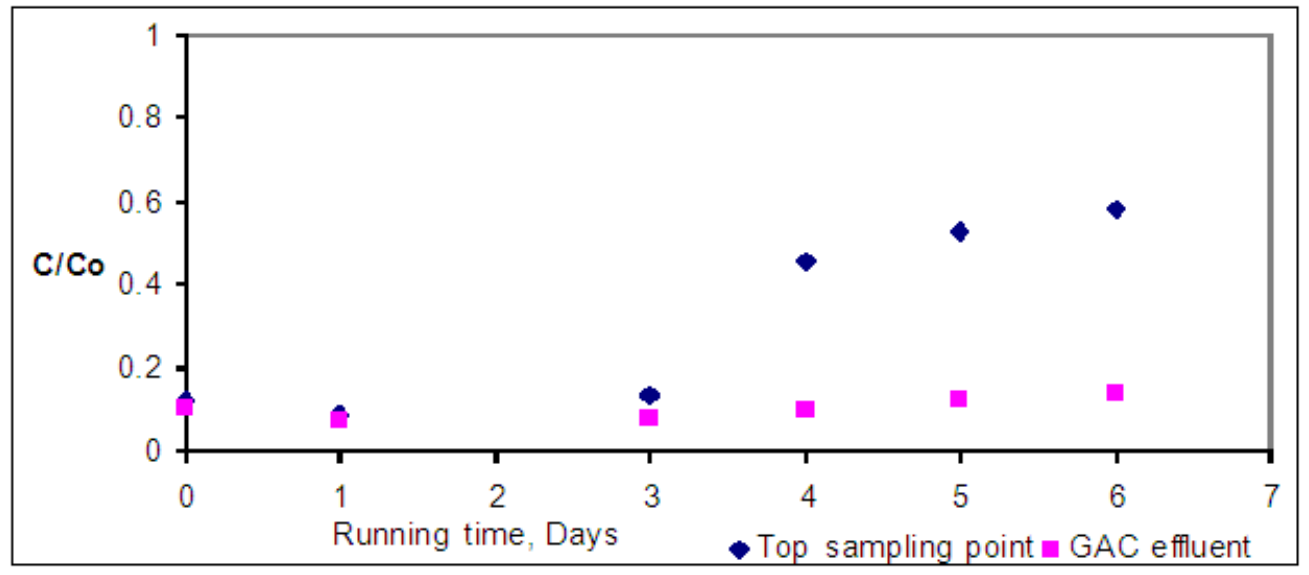

Figure 10. Effect of filter runtime and GAC depth on concentration for THMs at full-scale GAC filters (four year service media), top sampling point and after GAC sampling points; Coca-Cola Plant, Coca-Cola Plant, Antwerp, Feed water: $\mathrm{Co}=41.4 \pm 0.42 \mu \mathrm{g}$ THMs/L, $\mathrm{pH}=7.0 \pm 0.2$.

\subsection{Comparison GAC filters with new and old media}

Comparison of performance of GAC filters with four years old GAC showed large reduction in THMs removal efficiency in comparison to GAC with new media. This might be due to frequent regeneration and trapped contaminants. Moreover, steam/hot water regeneration does not restore capacity lost due to natural organic matter.

Comparison of two week $(\mathrm{Co}=59.7 \pm 8.60 \mu \mathrm{g}$ THMs/L) and four years in service $(\mathrm{Co}=50.75 \pm$ $8.95 \mu \mathrm{g}$ THMs/L) old GAC reveals THMs breakthrough of 3.8 and $58 \%$ at the end of one steam regeneration cycle for EBCT of $2.41 \mathrm{~min}$ as shown in figure 11. For old GAC media of $2.41 \mathrm{~min}$ 
EBCT the THMs' breakthrough increased from 5.1\% at the beginning of filter run after steam regeneration to $58 \%$ after one week operation time (over. At the same time new GAC media with the same EBCT of 2.41 min constant breakthrough of 3.8\% was observed. At the beginning of filter run 7.12 min EBCT of old GAC resulted in THM's breakthrough of up to $14 \%$ during one week of operation. These results show that steam regeneration cannot fully recover GAC adsorption capacity for THM's on longer term.

The main reason for decrease of the THM's adsorption capacity of GAC media in four year period might be due to trapped contaminants in GAC media that cannot be recovered by steam regeneration and breakage of carbon during back washing. And it might be due to development of steep breakthrough curve caused by frequent regeneration and backwash (VanLier, 1989; Edward, 2005).

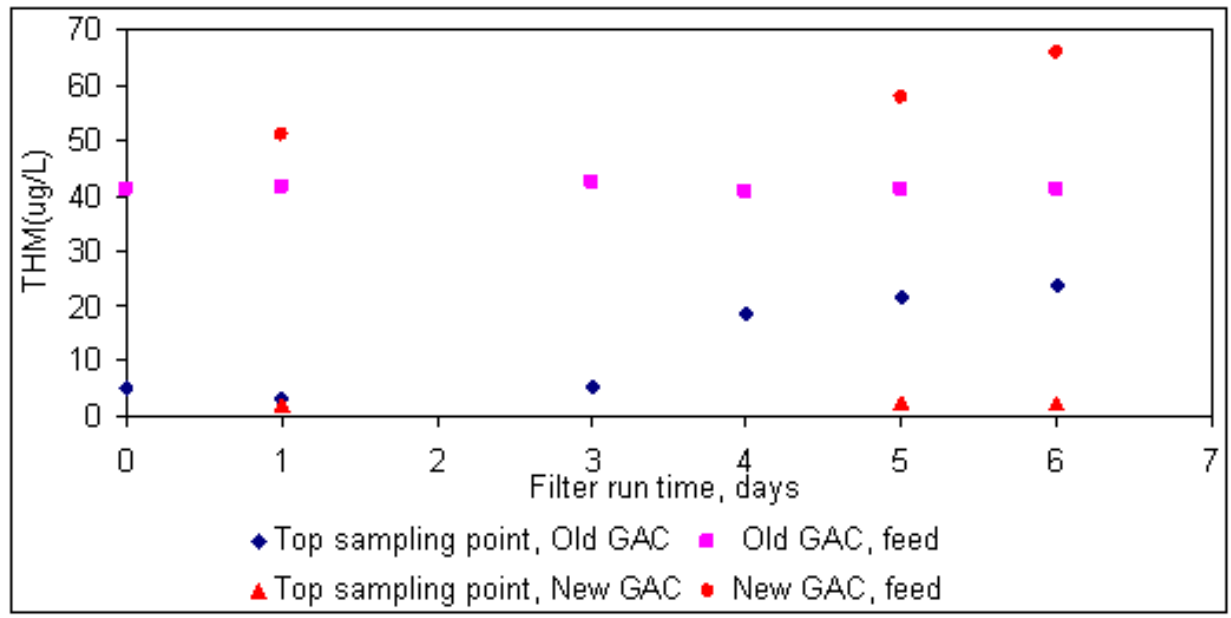

Figure 11. Effects of filter runtime and GAC age on THMs infiltrate concentration at the top sampling point (40cm depth) of full-scale GAC filter.

In Antwerp treatment plant since the feed water is low turbid and backwashing greatly reduce GAC performance it is advisable to minimize the frequency of backwash. The mass transfer zone will be disrupted due to back washing, which in turn causes premature breakthrough of contaminants. If Backwashing is necessary (due to high head loss or microbiology) it should be done carefully not to introduce oxygen to the GAC media which may cause precipitation of calcium carbonate (or metals) or significant biological growth. However backwash does not affect DOC removal (Letterman, 1999; Henke and Speitel, 1998).

Since, backwashing is the process of reversing the flow through a media bed with enough velocity to dislodge any material caught in void spaces or attached to the media. The backwash 
velocity shall be conducted according to supplier manual. However, during backwashing care shall be taken to minimize segregation and much disruption of mass transfer zone. In general, as per the suppliers of Calgon F200 backwash bed expansion of $20 \%$ shall be maintained for effective media clearing.

\section{CONCLUSION}

GAC is applied in carbonated beverage water industry for removal of chlorine, THMs and possibly other contaminants. Considering dechlorination and THMs removal need for GAC regeneration is controlled by THMs breakthrough. The result showed $28.4 \%$ TOC removal in the GAC filters comparing to TOC removal in the upstream of GAC filters. The SUVA value showed that the low removal of TOC before GAC filter (31\%) was due to the non humic nature, relatively low hydrophobicity, less aromatic and of lower molecular weight of the TOC. Regardless of upstream GAC filter's highest concentration $(18.89 \pm 3.53 \mu \mathrm{g} / \mathrm{L})$ of bromodichloromethane (BDCM) and the lowest concentration of bromoform $(4.00 \pm 0.60 \mu \mathrm{g} / \mathrm{L})$ the effluent concentrations of THMs species was found to be in the order: $\mathrm{CHCl}_{3}>\mathrm{CHBrCl}_{2}>\mathrm{CHBr}_{2} \mathrm{Cl}>\mathrm{CHBr}_{3}$. This showed the brominated methane's are more strongly adsorbed than chloroform. Four year continuous operation of the GAC filter in the Coca-Cola treatment in Antwerp plant resulted in strong reduction of THMs removal efficiency comparing to new GAC media. This suggests that steam regeneration is only partially recovering THMs adsorption capacity

\section{REFERENCES}

APHA. 1998. Standard methods for the examination of water and wastewater. 20th Ed., Washington.

Crittenden, J. C., Hand, D. W., Reddy, P. S., Arora, H., Trynoski, J. M \& Notthakun, S. 1989.

Prediction of GAC Performance using Rapid Small-Scale Tests. American Water Works Association annual conference Los-Angeles.

Edward, E. B. Technical Editor. 2005. Water Treatment Plant Design, New York.

Henke, J. L \& Speitel, G. E. 1998. Performance Evaluation of Granular Activated Carbon System at Pantex: Rapid Small-Scale Column Tests to Simulate Removal of High 
Explosives from Contaminated Groundwater. Amarillo National Resource Center for Plutonium, 81p.

Kim, J. K \& Kang, B. 2008. DBPs removal in GAC filter-adsorber. Water research42: 145-15.

Letterman, R. D. 1999. Water Quality and Treatment.A hand book of community water Supplies, McGRAW-HILL Companies, American water Works associaltion, USA.

Li, j. W., Yu Z., Gao M \& Cai X. 1997. Trihalomethanes Adsorption on Activated Carbon and Fiber and Granular Activated Carbon, water air and soil pollution. Academic publisher, The Netherlands, 97: 367-378

Liu, X., Yu, G \& Han, W. 2007. Granular activated carbon adsorption and microwave regeneration for the treatment of 2,4,5-trichlorobiphenyl in simulated soil-washing solution. Journal of hazardous materials, 147: 746-751.

Macquarrie, C \& Wilton, S. 2002. The Ins and Outs of De-chlorination. Hatchery International 26 ed., Nuts and Bolts

Metcalf \& Eddy. 2006. Wastewater Engineering Treatment and Reuse Tata McGraw-Hill Publishing Company Limited New Delhi, India.

Orlandini, E. 1999. Pesticide Removal by Combined Ozonation and Granular Activated Carbon Filtration.

Potwora J. R. 2006. Trihalomethanes Removal with Activated Carbon, Water conditioning and purification: http://www.wcponline.com/pdf/Potwora.pdf. Accessed 15 June 2011.

Qasim, S. R., Motley, E. M \& Zhu, G. 2004. Water Works Engineering Planning Desighn And Operation.

Roy, G. M. 1995. Activated Carbon Applications in the Food Pharmaceutical Industries, Technomic Publishing Company, inc., Lancaster, Pennsylvanai U.S.A.

Tebeje, Z. 2010. Competitive adsorption of chloroform and bromoform using commercial bituminous and coconut based granular activated carbon. East African Journal of Science, 4(2): 1-6.

Tebeje, Z. 2011. GAC adsorption processes for chloroform removal from drinking water. Tanzanian Journal of Natural and Applied Sciences, 2(1): 352-358.

USEPA. 1999. Alternative Disinfectants and Oxidants Guidance Manual.

VanLier, W. C. 1989. Mass Transfer to Activated Carbon in Aqueous Solution,Delft, the Netherlands. 